\title{
Concepto del Vaticano sobre los métodos Psico- físicos en obstetricia
}

\author{
Tomado de "El Catolicismo". № 637. Febrero 3 de 1956. Bogotá.
}

La Sagrada Escritura no prohibe el parto sin dolor

\begin{abstract}
Discurso del Padre Santo a un grupo de médicos del Secretariado Internacional
"Médicos Católicos" y de la A. M. C. I.
\end{abstract}

(8 de Enero de 1956)

Se nos ha informado acerca de un nuevo adelanto de la ginecología y nos han pedido que adoptásemos una posición en relación a ella desde el punto de vista moral y religioso. Se trata del parto natural, sin dolor, en el cual no se utiliza ningún medio artificial, sino únicamente se ponen en juego las fuerzas naturales de la madre.

\section{REFERENCIAS A DECLARACIONES ANTERIORES}

En nuestra alocución a los miembros del IV Congreso Internacional de Médicos Católicos, dei 29 de septiembre de 1949, decíamos que el médico se propone al menos mitigar los males y los zufrimientos que afligen al hombre. Mencionábamos entonces al cirujano, que se esfuerza por evitar lo más posible el dolor en las intervenciones necesarias; al ginecólogo, que procura disminuír los sufrimientos al dar a luz, sin poner en peligro ni a la madre ni al niño y sin menoscabar los lazos dei afecto maternal, que - según se afirma - se anudan precisamente en esos momentos. Esta última observación se refería a un procedimiento utilizado por entonces en la Casa de maternidad de una gran ciudad moderna: para evitar los dolores a la madre se le había provocado un estado de hipnosis profunda, pero se pudo constatar que este procedimiento llevaba consigo una indiferencia afectiva hacia el ni- 
ño. Algunos, sin embargo, piensan que se puede explicar este hecho de otra manera.

Aleccionados por esta experiencia en ocasiones sucesivas tuvieron cuidado de despertar a la madre varias veces durante algunos momentos a lo largo del desenvolvimiento del parto; se consiguió de tal manera evitar lo que se temía. Una constatación análoga se pudo obtener al hacer una narcosis prolongada.

El nuevo método, del cual queremos hablar ahora, no tiene ese peligro; deja a la parturienta su plena conciencia, desde el principio hasta el final, y el pleno uso de sus fuerzas psíquicas (inteligencia, voluntad, afectividad); no quita o, según otros, no disminuye más que el dolor.

\section{I}

\section{ESQUEMA DEL NUEVO METODO}

\section{Sus relaciones con la experiencila del pasado}

En primer lugar, el parto sin dolor, considerado como un hecho corriente, está en neto contraste con la común experiencia humana, la de hoy y también la del pasado y de los tiempos más remotos.

Las investigaciones más recientes indican que algunas madres dan a luz sin sentir ningún dolor, aunque no se haya utilizado analgésico o anestésico alguno. Demuestran también que el grado de intensidad de los sufrimientos es menor en los pueblos primitivos que en los civilizados; si éste es de intensidad media en muchos casos, resulta todavía elevado para la mayor parte de las madres, y hasta no es raro que sea insoportable. Tales son los hechos observados en la actualidad.

Lo mismo se debe decir de los tiempos pasados, en cuento las fuentes históricas nos permiten controlar el hecho. Los dolores de las mujeres en el parto eran proverbiales; se hacía referencia a ellos para expresar un sufrimiento muy vivo y angustioso, y la literatura, tanto profana como religiosa, nos da prueba de ello. Ese modo de hablar es corriente, en efecto, aun en los textos bíblicos del Antiguo y del Nuevo Testamento, sobre todo en los escritos de los profetas. Nos citaremos aqui algunos ejemplos: Isaías compara su pueblo con la mujer que, en el instante del 
alumbramiento, sufre y se queja (cfr. Is. 26, 17). Jeremías, que ve delante el aproximarse del juicio de Dios ,dice: "Oigo gritos como de mujer en parto; alaridos como los de una mujer que da a luz por vez primera" (Ier. 4, 31). En la tarde anterior a su muerte, el Señor compara la situación de sus Apóstoles a la de la madre que espera el momento del alumbramiento: "La mujer cuando pare siente tristeza, porque llega su hora. Pero cuando ha dado a luz un hijo, ya no se acuerda de la tribulación por el gozo que tiene de haber venido al mundo un hombre" (Io., 16, 21).

Todo esto permite afirmar, como un hecho aceptado entre los hombres de ayer y de hoy, que la madre engendra en el dolor, y a esto se opone el nuevo método.

\section{El nuevo método, considerado en sí mismo}

a) Consideraciones generales preliminares hechas por sus partidarios.

Dos consideraciones generales hechas por los partidarios de este método guian y orientan al que quiere delinear sus rasgos principales: la primera se refiere a la diferencia entre actividad indolora y actividad dolorosa de los órganos y de los miembros; la otra, al origen del dolor y su relación con la función orgánica.

Las funciones del organismo, se dice, cuando son normales y se realizan como deben, no van acompañadas de sensaciones dolorosas; éstas denotan la presencia de alguna complicación; de otra forma, la naturaleza estaría en contradicción consigo misma, dado que asocia el dolor a un proceso determinado con el fin de provocar una reacción de defensa y de protección contra todo lo que sería nocivo. El parto normal es una función natural y, por tanto, debería producirse sin dolor. ¿De dónde viene éste?

La sensación de dolor - se responde - viene de la corteza cerebrai y está regulada por ella, siendo allí donde llegan las excitaciones y señales de todo el organismo. Sobre éstas, el órgano central reacciona de manera muy distinta; algunas de estas reacciones (o reflejos) reciben de la naturaleza un carácter preciso y están asociadas por ella a procesos determinados (reflejos absolutos); para otras, por el contrario, la naturaleza no ha fijado ni su carácter ni sus conexiones, sino que están determinadas de otra manera (reflejos condicionados). 
Las sensaciones de dolor están en el número de los reflejos (absolutos o condicionados), que tienen su origen en la corteza cerebral. La experiencia ha probado que, gracias a las asociaciones establecidas arbitrariamente, es posible provocar sensaciones de dolor aun cuando la excitación que las provoca sea de por sí totalmente incapaz de ello.

En las relaciones humanas, esos reflejos condicionados tienen por agentes más eficaces y más frecuentes el lenguaje, la palabra hablada o escrita o, si se quiere, la opinión que reina en un ambiente y que todos condividen y expresan por medio del lenguaje.

\section{b) Elementos del nuevo método.}

Así se comprende el origen de las vivas sensaciones de dolor sentidas en el alumbramiento: éstas son consideradas por ciertos autores como reflejos condicionados desencadenados por erróneos complejos ideológicos y afectivos.

Los discípulos del ruso Paviov (fisiólogos, psicólogos, ginecólogos), sacando partido de las investigaciones de su maestro sobre los reflejos condicionados, presentan en sustancia la cuestión de la manera siguiente:

\section{a') Su fundamento.}

El parto ha sido siempro doloroso, pero se ha hecho tal en el curso de los tiempos a causa de los reflejos condicionados. Estos han podido tener su origen en un primer parto doloroso; quizá la herencia tiene allí también su parte, pero éstos no son más que factores secundarios. El motivo principal de ello es el lenguaje y la opinión del ambiente que él manifiesta: el alumbramiento -dice- es "la hora difícil de la madre", es una tortura impuesta por la naturaleza, que entrega a la madre, indefensa, a sufrimientos insoportables. Esta asociación, creada por el ambiente, provoca el temor a los dolores terribles que lo acompañan. Así, cuando las contracciones musculares del útero se hacen sentir, al principio del parto surge la reacción de defensa del dolor; este dolor provoca una contracción muscular y ésta, a su vez, un acrecentamiento de los dolores. Los dolores, pues, son reales, pero derivan de una causa falsamente interpretada. En el parto son un hecho las contracciones normales del útero y las sensaciones orgánicas que la acompañan; pero estas sensaciones no son interpretadas por los órganos centrales como lo que realmente son: 
unas simples funciones naturales; en virtud de los reflejos condicionados, y en particular del enorme "miedo", tales sensaciones van a parar al campo de las sensaciones dolorosas.

\section{b') Su objeto.}

Tal seria la génesis de los dolores puerperales.

De aquí se deduce cuál ha de ser el fin y la tarea de la obstetricia sin dolor. Aplicando los conocimientos científicos adquiridos, debe primero disociar las asociaciones que ya existen entre las sensaciones normales de las contracciones del útero y las reacciones de dolor de la corteza cerebral. De este modo se anulan los reflejos condicionados negativos. Al mismo tiempo hay que crear nuevos reflejos, positivos, para sustituír los reflejos negativos.

\section{c') Șu aplicación práctica.}

La aplicación práctica consiste en dar en primer lugar a las madres (mucho antes de la época del alumbramiento) una enseñanza profunda, adaptada a su capacidad intelectual, sobre los procesos naturales que se desarrollan en ella durante el embarazo y de un modo particular durante el parto. Ellas conocian ya estos procesos naturales de alguna manera, pero las más de las veces sin percibir claramente su conexión. Así, muchas cosas quedaban todavía envueltas en una oscuridad misteriosa y se prestaban incluso a falsas interpretaciones .Los reflejos condicionados característicos adquirían también una fuerza de acción considerable, mientras la angustia y el temor encontraban allí un alimento constante. Todos los elementos negativos podrían eliminarse por la información antedicha.

Al mismo tiempo se hace un insistente llamamiento a la voluntad y al sentimiento de la madre con el fin de que no permita surjan sentimientos de temor infundados o que como tales les han sido presentados; hay también que rechazar una impresión de dolor que quizá tendería a manifestarse, pero que en todo caso no está justificada y no se basa, como se les ha enseñado, más que en una falsa interpretación de las sensaciones orgánicas naturales del útero que se contrae. Sobre todo se procura llevar a la madre a estimar la grandeza natural y la dignidad de lo que se cumple en el momento de dar a luz. Se les dan también explicaciones técnicas detalladas de lo que es necesario hacer para asegurar el 
perfecto desarrollo del alumbramiento; se les enseña, por ejemplo, cómo han de poner exactamente en movimiento la musculatura, cómo han de respirar bien. Esa enseñanza se da bajo la forma de ejercicios prácticos para que la técnica haya llegado a serles familiar en el momento del parto. Se trata, pues, de guiar a las madres y de ponerlas en condiciones de que soporten el parto, no de un modo puramente pasivo como si se tratase de un proceso fatal, sino adoptando una postura activa, influyendo en él con la inteligencia, la voluntad, la afectividad, de suerte que se lleve a buen término, en el sentido que requiere la naturaleza, y con su ayuda.

Durante el proceso del parto, la madre no está abandonada a sí misma; está asistida y con el control de un personal formado según las nuevas técnicas y que le recuerda lo que ha aprendido, le indica en el momento oportuno todo lo que tiene que hacer, evitar o modificar y que en caso necesario rectifica rápidamente sus errores y le ayuda a corregir las anomalías que se pudieran presentar.

Tal es en lo esencial, según los investigadores rusos, la teoría y la práctica del parto sin dolor. Por su parte, el inglés Grantly Dick Read ha presentado una teoría y una técnica análogas a aquélla en un cierto número de puntos; sin embargo, en sus presupuestos filosóficos y metafísicos se aleja sustancialmente de la misma, ya que no se apoya como aquéllos en una concepción materialista.

\section{d’) Extensión y éxito.}

Por lo que se ref̣iere a la extensión y al éxito del nuevo método (llamado método psicoprofiláctico), se afirma que en Rusia y China se ha utilizado ya en centenares de millares de casos. Se ha impiantado también en diversos países de Occidente; se llega a afirmar que varias maternidades municipales han puesto a su disposición particulares secciones. Las Casas de maternidad, organizadas exclusivamente según ese principio, son poco numerosas hasta el día de hoy en Occidente; Francia, entre otras, tiene una (comunista) en París; también en Francia, dos instituciones católicas, en Jallieu y Cambrai, han adoptado completamente este método en sus departamentos, sin sacrificar lo que había resultado bueno anteriormente. 
En cuanto al éxito se afirma que es muy relevante: de los aiumbramientos acaecidos de esta manera, de un 80 a un 90 por 100 lo han sido - según se dice- realmente sin dolor.

\section{VALORACION DEL NUEVO METODO}

\section{Valoración científica}

Después de haber trazado el esquema de este método pasamos a su valoración. En la documentación que se nos ha enviado se encuentra esta nota característica: "Para el personal, la primera exigencia indispensable es la fe incondicional en el método". ¿Será posible exigir una fe absoluta de este género basándola sobre resultados cientificos seguros?

El método contiene, sin duda, elementos que se deben considerar como científicamente probados; algunos tienen sólo una gran probabilidad; otros no son más (por io menos en este momento) que de indole problemática. Está científicamente comprobado que existen reflejos condicionados en general; que representaciones o estados afectivos determinados pueden asociarse con ciertos acontecimientos, y que este caso puede verificarse para las sensaciones de dolor. Pero que esté ya probado (o por io menos que se pueda probar de esta manera) que los dolores del alumbramiento son debidos únicamente a esta causa, no es una verdad evidente para todos en la hora actual. También algunos críticos serios formulan reservas respecto al axioma que afirma, casi "a priori": "Todos los actos fisiológicamente normales y, por tanto, el nacimiento normal, deberían realizarse sin dolor, pues en caso contrario, la naturaleza estaría en contradicción consigo misma". Ellos no admiten que sea universalmente válida sin excepción, ni que la naturaleza esté en contradicción consigo misma en el caso de que haya hecho del parto un acto intensamente doloroso. En efecto, dicen, sería perfectamente comprensible fisiológica y psicológicamente que la naturaleza, preocupada de la madre que engendra y dei niño engendrado, haga esto para que se tenga conciencia de una manera ineluctable de la importancia de este acto y quiera así obligar a que se tomen las medidas necesarias con relación a la madre y al niño. Dejemos a los especialistas competentes la comprobación científica de estos dos axiomas, que unos sostienen como ciertos y otros discutibles; sin embargo, es necesario, para decidir acerca de la verdad o falsedad, atenerse a un criterio objetivo deci- 
sivo: "El carácter científico y el valor de un descubrimiento se deben apreciar exclusivamente en relación a su conformidad con la realidad objetiva". Es importante no descuidar aquí la distinción entre "verdad" y "afirmación", ("interpretación", "subsunción", "sistematización") de la verdad. Si la naturaleza ha hecho el parto sin dolor en la realidad de las cosas, si después ha llegado a ser doloroso a causa de los reflejos condicionados, si puede transformarse en parto sin dolor, si todo esto no es así, o no es, al menos por ahora, posible obtener una certeza completa a este respecto, es necesario abstenerse de toda afirmación absoluta y considerar las conclusiones obtenidas como 'hipótesis' científicas.

Renunciando por el momento a dar un juicio definitivo sobre el grado de certeza científica del método psicológico-profiláctico, pasamos a examinar el problema desde el punto de vista moral.

\section{Valoración ética}

Este método ¿es moralmente irreprensible?

La contestación, que debe tener en cuenta el objeto, el fin y el motivo, se anuncia brevemente: "En sí mismo no tiene nada de reprobable desde el punto de vista moral".

La enseñanza dada sobre la obra de la naturaleza en el parto, o la corrección de la interpretación falsa de las sensaciones orgánicas y la invitación a corregirlas, la influencia ejercida para hacer desaparecer la angustia y el temor infundados, la ayuda concedida para que la parturienta colabore oportunamente con la naturaleza, conserve su calma y el dominio de sí misma; una creciente conciencia de la grandeza de la maternidad en general y en particular de la hora en que la madre da a luz al hijo; todos estos son valores positivos a los cuales no hay nada que reprochar; son ventajas para la parturienta plenamente conformes a la voluntad del Creador. Visto y entendido de esta manera, el método es una ascesis natural que protege a la madre contra la superficialidad y la ligereza, ejerce un influjo positivo sobre su personalidad, para que en una hora tan importante como es la del alumbramiento, manifieste la firmeza y la solidez de su carácter. Todavía bajo otros aspectos, el método puede dar resultados moralmente positivos. Si se logra eliminar el dolor y el temor al alumbramiento, se disminuye a menudo, por lo mismo, el incentivo a cometer acciones inmorales en el uso de los derechos del matrimonio. 
En lo que se refiere a los motivos y al fin de las ayudas concedidas a la parturienta, la acción material, como tal, no comporta ninguna justificación moral, ni positiva ni negativa; esto concierne a quien preste su ayuda. Puede y debe llevarse a cabo por motivos y en vista a un fin irreprochable, tales como el interés presentado por un hecho puramente científico; el sentimiento natural y noble que hace estimar y amar en la madre a la persona humana a la que se quiere hacer el bien y asistirla; una disposición profundamente religiosa y cristiana que se inspira en ideales de un cristianismo vivo. Pero puede suceder que la asistencia busque un fin y obedezca a motivos inmorales; en este caso, es la actividad personal del que presta la ayuda la que sufre el perjuicio; el motivo inmoral no transforma la asistencia buena en una cosa mala, al menos en lo que se refiere a su estructura objetiva; e, inversamente, una asistencia buena en sí. no puede justificar un motivo malo o dar la prueba de su bondad.

\section{Valoración teológica}

Falta decir una palabra acerca de la valoración teológica y religiosa en aquello que la distingue del valor moral en sentido estricto. El nuevo método se presenta a menudo como formando parte de una filosofía y de una cultura materialista y en oposición a la Sagrada Escritura y al cristianismo.

La ideología de un investigador y de un sabio no es en sí una prueba de la verdad y del valor de lo que ha descubierto y expuesto. El teorema de Pitágoras o (para no salir del campo de la medicina) las observaciones de Hipócrates, que se han reconocido exactas; los descubrimientos de Pasteur, las leyes de la herencia de Mendel no deben la verdad de su contenido a las ideas morales y religiosas de sus autores. No son ni "paganas" porque Pitágoras e Hipócrates fueron paganos, ni cristianas porque Pasteur y Mendel fueron cristianos. Estos adelantos científicos son verdaderos porque responden a la realidad objetiva $y$ en tanto en cuanto a ella corresponden.

Del mismo modo, un investigador materialista puede hacer un descubrimiento científico real y verdadero; pero esta aportación no constituye de ninguna manera un argumento a favor de sus ideas materialistas.

El mismo razonamiento vale para la cultura a la cual pertenece un sabio. Sus descubrimientos no son verdaderos ni falsos porque hayan salido de tal o cual cultura, de la cual él ha recibido la inspiración y que ha impreso en él un sello profundo. 
Las leyes, la teoría y la técnica del parto natural, sin dolor, son válidas, sin duda; pero han sido elaboradas por sabios que en su mayoría profesan una ideología y pertenecen a una cultura materialista. Esta ideología y esta cultura no son verdaderas porque los resultados científicos citados anteriormente lo sean. $Y$ aún es mucho menos exacto que ios resultados científicos sean verdaderos y hayan sido demostrados tales porque sus autores y las culturas de las que ellos provienen tengan una orientación materialista. Los criterios de la verdad son otros.

El cristiano convencido no encuentra nada en sus ideas filosóficas y en su cultura que le impida ocuparse seriamente, en la teoría y en la práctica, del método psicoprofiláctico; él sabe, como regla general, que la realidad y la verdad no son idénticas en su interpretación, subsunción o sistematización, y que, por consiguiente, puede al mismo tiempo aceptar completamente lo uno y rechazar enteramente lo otro.

\section{El nuevo método y la Sagrada Escritura}

Una crítica del nuevo método, desde ei punto de vista teológico, debe en primer lugar tener en cuenta la Sagrada Escritura, porque la propaganda materialista pretende encontrar una contradicción deslumbradora entre las verdades de la ciencia y las de la Escritura. En el Génesis (Gen. 3, 16) se lee: "In dolore paries filios" ("Darás a luz en el dolor"). Para entender bien estas palabras es nocesario considerar la condena impuesta por Dios en el conjuntt del contexto. Infligiendo este castigo a los primeros padres y a su descendencia, Dios no quiso impedir, ni ha impedido a los hombres, el investigar y utilizar todas las riquezas de la creación, hacer que la cultura progrese paso a paso; contribuir a que la vida de este mundo sea más soportable y hermosa; suavizar el trabajo y la fatiga, el dolor, la enfermedad y la muerte; en una palabra, someter a sí la tierra (Gen. I, 28).

Del mismo modo, castigando a Eva, Dios no quiso impedirle, y no ha impedido a las madres, el utilizar los medios apropiados para hacer el parto más fácil y menos doloroso. A las palabras de la Escritura no es necesario buscar una escapatoria; permanecen verdaderas en el sentido entendido y expresado por el Creador; la maternidad dará mucho que sufrir a la madre. ¿De qué manera precisa ha concebido Dios este castigo y cómo 10 ejecutará? La Escritura no lo dice. Algunos pretenden que el parto fue en sus orígenes completamente sin dolor y que se hizo 
doloroso más tarde (tal vez a consecuencia de una interpretación errónea del juicio de Dios) merced a la auto - y hetero- sugestión, de las asociaciones arbitrarias, de los reflejos condicionados y a consecuencia del comportamiento equivocado de las parturientas; hasta aquí, sin embargo, estas afirmaciones, en su conjunto, no han sido comprobadas. Por otra parte, puede ser verdad que un incorrecto comportamiento psíquico o físico de las parturientas sea suscaptible de aumentar mucho las dificultades del parto y las haya aumentado en realidad.

La ciencia y la técnica pueden, pues, servirse de las conclusiones de la psicología experimental, de la fisiología y de la ginecología (como en el método psicoprofiláctico) con el fin de eliminar las fuentes de errores y los reflejos condicionados doiorosos, y de hacer que el alumbramiento sea lo menos doloroso posible; la Escritura no lo prohibe.

\section{Consideraciones finales sobre la obstetricia cristiana}

Como conclusión añadimos algunas observaciones sobre la obstetricia cristiana.

La caridad cristiana siempre se ha preocupado de las maares en el momento del parto. Se ha esforzado e incluso hoy se esfuerza por procurarles una asistencia eficaz física y psíquica, según el estado de progreso de la ciencia y de la técnica. Quizá sea este el momento de los nuevos adelantos del método psícoprofiláctico en la medida en que éstas encuentren la aprobación de los estudiosos serios. La obstetricia cristiana puede incluír en sus principios y en sus métodos todo lo que es correcto y justificado.

Sin embargo, es de desear que no se contente con esto sólo para las personas capaces de recibir más y que no deje ninguno de los valores religiosos que ponía en juego hasta la hora presente. En nuestra alocución al Congreso de la Asociación Internacional de Comadronas Católicas del 29 de octubre de 1951 hemos hablado con detalle del apostolado que las comadronas católicas son capaces de prodigar y que están llamadas a realizar en el ejercicio de su profesión; por ejemplo, recordábamos el apostolado personal, es decir, el que ejerce por medio de su ciencia, de su arte, de la solidez de su fe cristiana; después, el apostolado en pro de la maternidad, la seriedad y la grandeza de la misma. Aqui se aplica lo que hemos dicho hoy, ya que ellas asisten a la madre en la hora del alumbramiento. La madre cris- 
tiana recibe de su fe y de su vida de gracia la luz y la fuerza para poner en Dios una plena confianza, para sentirse bajo la protección de la Providencia y aceptar con gusto lo que Dios le mande sufrir; seria un dolor que la obstetricia cristiana se limitara a ofrecerle un servicio puramente natural psicoprofiláctico.

Dos puntos merecen aquí ser subrayados: el cristianismo no interpreta el sufrimiento o la cruz de un modo puramente negativo. Si la nueva técnica le evita los sufrimientos del parto o los atenúa, ia madre puede aceptarla sin ningún escrúpulo de conciencia; pero no está obligada a ello. En caso de éxito parcial o de fracaso, sabe que el sufrimiento puede ser una fuente de bien si lo soporta con Dios y obedeciendo a su voluntad. La vida $y$ al sufrimiento del Señor, los dolores que tantos hombres grandes han soportado y hasta han buscado, gracias a los cuales se han madurado y han subido hasta las cumbres del heroírmo cristiano; los ejemplos cotidianos de aceptación resignada de la cruz, que se ofrecen a nuestra vista, todo revela la significación del sufrimiento, de la aceptación paciente del dolor en la economía actuai de la salvación durante el tiempo de esta vida terrena.

Segunda observación: El pensamiento y la vida cristiana, y consiguientemente la obstetricia cristiana, no atribuyen un valor absoluto a los progresos de la ciencia y a los refinamientos de la técnica. Por el contrario, un pensamiento y una concepción de la vida, según inspiración materialista, encuentran esta postura natural. Sirve a los que la profesan como de religión o de sucedáneo de la religión. El cristianismo, aunque aplauda los nuevos descubrimientos científicos y los utilice, rechaza todo lo que sea apoteosis materialista de la ciencia y de la cultura. Sabe que éstas ocupan un lugar en la escala objetiva de los valores; pero sin que este lugar sea el último, no es tampoco el primero. También, en cuanto a ellas, el cristiano repite hoy como ayer y como siempre: Buscad ante todo el reino de Dios y su justicia (Math. 6, 33). El más alto, el último valor del hombre, se encuentra no en su ciencia y en sus capacidades técnicas, sino en el amor de Dios y en la entrega a su servicio. Por estas razones el cristiano, ante el descubrimiento científico del parto sin dolor, se guarda de admirarlo sin reserva o de utilizario con una prisa exagerada; lo juzga de una manera positiva y con reflexión, a la luz de la recta razón natural y de aquella otra luz más viva de la fe y del amor que emana de Dios y de la cruz de Cristo.

(Traducción de ia Oficina de Prensa del Vaticano). 